\title{
Entre venalidad y corrupción: la venta de dos puestos de juez oficial de la Casa de la Contratación en la década de 1630*
}

\author{
Between Venality and Corruption: the Sale of Two Offices \\ of Official Judge of the Casa de la Contratación \\ in the Decade of 1630
}

\author{
Alfonso Jesús Heredia López \\ ORCID iD: http://orcid.org/0000-0002-0461-3600 \\ Universidad de Almería
}

Analizamos en este trabajo el proceso venal para el acceso a plazas de juez oficial de la Casa de la Contratación enajenadas en la década de 1630, y el posterior ejercicio del cargo por sus compradores. Destacamos cómo la venalidad de dichos oficios favoreció que determinados personajes con intereses en el comercio indiano se hicieran con empleos de la institución sevillana que debía encargarse de supervisar y controlar dicho comercio, utilizando su poder en un provecho propio que distaba mucho de los intereses que trataba de defender la Corona a través de la Casa de la Contratación.

Palabras Clave: Venalidad; Corrupción; Jueces Oficiales; Casa de la Contratación.

In this paper we analyse the venal process used to access the official judge positions of the Casa de la Contratación that were sold in 1630s, and the subsequent exercise of these positions by its buyers. We emphasise how the venality of these offices favoured that certain personalities with interests in the Indian trade obtained jobs from the Sevillian institution, which was in charge of supervising and controlling this trade, using their power to benefit themselves, something that was far from the interests that sought to defend the Crown through the Casa de la Contratación.

Keywords: Venality; Corruption; Official Judge; Casa de la Contratación.

Copyright: (C) 2019 CSIC. Este es un artículo de acceso abierto distribuido bajo los términos de la licencia de uso y distribución Creative Commons Reconocimiento 4.0 Internacional (CC BY 4.0).

* El presente estudio se ha realizado en el marco del Proyecto de Investigación de I+D «Dinámicas de corrupción en España y América en los siglos XVII y XVIII: prácticas y mecanismos de control» (HAR2017-86463-P), financiado por el Ministerio de Ciencia, Innovación y Universidades. 


\section{Introducción}

Es de sobra conocido que uno de los principales problemas de la monarquía hispánica durante los siglos XVI y XVII fue el hacendístico a causa de las empresas bélicas que emprendió y, aunque los recursos eran inmensos, los gastos superaban a los ingresos. La carencia financiera de la Corona provocó el recurso creciente al crédito, pero también la búsqueda de nuevas fuentes de ingresos en forma de tributos o bien en forma de arbitrios y expedientes extraordinarios. ${ }^{1}$ Igualmente, sabemos que la venalidad de cargos y honores se convirtió durante el Antiguo Régimen en un recurso extraordinario de ingresos de la fiscalidad regia. No es nuestro propósito hacer un estado de la cuestión sobre el tema, pues no hace muchos años que una obra monográfica editada por Francisco Andújar y María del Mar Felices y un artículo de Antonio Jiménez Estrella se encargaron de presentar un excelente balance de la investigación sobre la venalidad en la España del Antiguo Régimen. ${ }^{2}$

En los casos que aquí analizamos, la venalidad de los cargos de la Casa de la Contratación proporcionó a sus compradores el control de puestos estratégicos de la institución, lo que les ubicaba en una situación privilegiada de poder, honor y preeminencias tanto en Sevilla como en Cádiz. Dos de los personajes que pasaremos a analizar, Diego de Villegas y Pedro Fernández Moreno, además de servir — por compra el primero y por arrendamiento a su propietario el segundo- puestos de jueces oficiales de la Casa en Sevilla y Cádiz respectivamente, tuvieron fuertes intereses en el comercio indiano, lo que conculcaba las prohibiciones que tenían los ministros del rey en la Casa de la Contratación de participar en dicho comercio. La elección de la trayectoria de estos dos oficiales responde a la importancia que tenía el oficio de juez oficial de la Casa y a que fue la primera vez que se vendieron puestos de tan alta responsabilidad en la institución sevillana, pues aunque, con anterioridad a la venta de estos oficios, las visitas a la Casa habían demostrado la existencia de prácticas corruptas entre los jueces oficiales de provisión no venal, ${ }^{3}$ la venalidad de estas plazas supuso la entrada en ellas de personajes relacionados con el comercio indiano que no dudaron en continuar con dichas actividades mercantiles desde su nuevo papel de ministros de la monarquía.

1 Para el reinado de Felipe IV sigue siendo imprescindible: Domínguez Ortiz, 1960. Ruiz Martín, 2008. Gelabert González, 1997.

2 Andújar Castillo y Felices de la Fuente, 2011. Jiménez Estrella, 2012.

3 Véase Schäfer, 2003 [1935], 327. 


\section{La venta de cargos de la Casa de la Contratación en la primera mitad del siglo XVII}

Durante el valimiento de Olivares y, con mayor profusión, desde la entrada de la monarquía hispánica en la guerra de los Treinta Años, la venalidad de cargos alcanzó cotas inusitadas. Amén del meritorio libro de Schäfer, ${ }^{4}$ que sacó a la luz distintas enajenaciones de cargos de la institución sevillana, el estudio de Francisco Andújar ${ }^{5}$ sobre la venalidad de los cargos de la Casa de la Contratación destacó que la Casa fue la institución de la monarquía que con mayor virulencia experimentó la venta de sus principales oficios durante el siglo XVII, bien en forma de beneficio o bien como venta a perpetuidad. ${ }^{6}$ Fueron precisamente las perpetuaciones de oficios las que vinieron a privatizar buena parte de los empleos de la institución sevillana durante el valimiento de Olivares.

La Casa de la Contratación, dependiente del Consejo de Indias, se vio envuelta en la almoneda de cargos que protagonizaron tanto el sínodo indiano como determinados comisionados y juntas ocupadas en tal efecto. ${ }^{7}$ El propio presidente de la Casa entre 1635 y 1637, Pedro de Vivanco, se ocupó de vender toda clase de efectos y actuó en paralelo a los demás comisionados que enajenaban «productos» similares. El consejero de Indias, Juan Pardo Arenillas estuvo comisionado entre 1638 y 1640 para este cometido. Por otro lado, la Junta de Vestir la Casa, en cuyas plazas se sentó el consejero de Indias Lorenzo Ramírez de Prado, tuvo, aunque en menor grado, cierta influencia en la venta de cargos de la Casa de la Contratación. ${ }^{8}$

Pero la gran empresa enajenadora fue comandada por el presidente del Consejo de Indias entre noviembre de 1632 y 1653, el conde de Castrillo. ${ }^{9}$ Las operaciones de venta de cargos que llevó a cabo Castrillo incluyeron puestos de la sala de gobierno de la institución, como los de contador, oficios de la Armada, de la administración de Avería, así como otros efectos relacionados con la Carrera de Indias, como los maestrajes de plata ${ }^{10} \mathrm{o}$ las naturalezas de Indias. ${ }^{11}$ Las perpetuaciones de oficios de la Casa generaron

4 Schäfer, 2003 [1935].

5 Andújar Castillo, 2014.

6 Sobre esta diferenciación véase: Andújar Castillo, 2011.

7 Gil Martínez, 2017a.

8 Esta institución ha sido recientemente estudiada por Gil Martínez, 2017b.

9 Gil Martínez, 2017a, 99.

10 Álvarez Nogal, 2000. Vila Vilar, 1997. Gil Martínez, 2016.

11 Díaz Blanco, 2011. 
un elevado volumen de ingresos a la particular cuenta de Castrillo en el Consejo de Indias. ${ }^{12}$

En las siguientes páginas analizaremos mediante dos estudios de caso cómo merced a la venalidad de cargos de la Casa de la Contratación y la privatización de los mismos, acaudalados personajes con intereses en el comercio con Indias se hicieron con empleos de la institución que debía supervisar y controlar dicho tráfico mercantil. A su vez, detallaremos cómo estos cargos fueron utilizados por sus propietarios para obtener unos aprovechamientos ilícitos derivados del puesto que desempeñaban, cayendo en prácticas que podríamos denominar como «corruptas», burlando así las leyes y ordenanzas que les impedían, desde su posición de oficiales de la monarquía en la Contratación, mezclarse en el comercio. ${ }^{13}$

\section{Diego de Villegas: contador juez oficial de la Casa por el mérito pecuniario}

Sin duda, el cargo más importante de los enajenados en la década de 1630, por su pertenencia a la sala de gobierno de la Casa y por la asombrosa suma depositada por su comprador, fue el puesto de contador juez oficial enajenado a perpetuidad a Diego de Villegas. Por vez primera desde la creación de la Casa de la Contratación en 1503 se privatizó uno de los tres principales puestos de la institución sevillana. ${ }^{14}$

Tras la muerte del contador Antonio de Calatayud, el 1 de febrero de 1633, el oficio pasó a servirlo interinamente Andrés de Munibe, en esos momentos oficial mayor de la Contaduría de la Casa. ${ }^{15}$ El que luego iba a ser tesorero de la Casa a partir de 1640 intentó, aprovechando su ejercicio en interinidad del cargo de contador, hacerse con el puesto. Así se lo manifestó al consejero de Indias Cristóbal de Moscoso en una misiva en la que, aludiendo a sus años de servicio a la monarquía en la Casa de la

12 Por mano del conde de Castrillo corrieron perpetuaciones tan importantes como las del oficio de veedor general de las armadas y flotas de la Carrera de Indias, adquirido por Alonso de Tapia Vargas por la cantidad de 12.000 ducados o el de alguacil mayor de las armadas y flotas de Indias, comprado por Pedro de la Mata Velasco en 10.000 ducados. Al respecto, véase: Gil Martínez, 2017a, 111.

13 Así lo expresaba la ley XXXII del libro IX, título II de la Recopilación de leyes de Indias: «Que el presidente y jueces de la Casa, y los de Cádiz, y de Canarias y visitadores y sus criados no contraten en las Indias».

14 Andújar Castillo, 2014.

15 Vila Vilar, 2003a, 440. 
Contratación, pedía que mediara ante el rey en su pretensión de que le hiciera merced en propiedad del cargo de contador. ${ }^{16}$ Además, Munibe ejercía el puesto de tenedor del libro de caja de la Real Hacienda de la Casa y, en agosto de 1634, Francisco de la Parra estuvo ocupando ese puesto en interinidad. Según afirmó en su nombramiento el presidente de la Casa, el conde de Peñaflor, la designación de Francisco de la Parra fue por la dejación de Munibe al haber salido hacia Madrid a suplicar al rey que le hiciera merced equivalente al cargo de contador que había sido enajenado a Diego de Villegas. ${ }^{17}$ Es más que probable que, en la negociación establecida en ese viaje a la Corte para suplicar una merced de similares características a la obtenida por Diego de Villegas, se sitúe el origen de la plaza de juez oficial supernumerario que Munibe obtuvo en 1636. ${ }^{18}$

De lo que no hay duda es de que el cargo de juez oficial de la Casa era cotizado entre las familias sevillanas que en la década de 1630 estaban intentando medrar en puestos de importancia en la Casa de la Contratación, como era el caso de Andrés de Munibe, que de hecho, como veremos más adelante, volvería después a intentar hacerse con la plaza de juez de Cádiz cuando esta fue puesta en almoneda. Sin embargo, la oportunidad de obtener una suma considerable por el puesto de contador de la Casa pesó más que los 36 años de servicio continuados a los que hacía alusión Munibe en su epístola a Moscoso.

Diego de Villegas, natural de Entrambasmestas, en el burgalés valle del Toranzo, ${ }^{19}$ ya había desempeñado con anterioridad cargos para la monarquía en Lima y Nueva España. Primeramente sirvió como capitán de infantería en Lima, ${ }^{20}$ donde su hermano, Bernardo de Villegas, era un importante financiero ${ }^{21} \mathrm{y}$, posteriormente, fue alcalde mayor de la frontera de indios libres cerca de Nombre de Dios, en Nueva España. ${ }^{22}$ A su vuelta a Sevilla, en 1634, se hizo con el puesto de contador juez oficial, uno de los principales cargos de la sala de gobierno de la Casa de la Contratación, por la muy considerable suma de 50.000 ducados de plata más 5.000 ducados

16 Archivo General de Indias (AGI), Indiferente, 2010.

17 AGI, Contratación, 5785, lib. 1, f. 97r-v.

18 Sobre la plaza de juez supernumerario de Munibe, véase Vila Vilar, 2003a.

19 Archivo Histórico Nacional (AHN), Órdenes Militares (OM) Caballeros Alcántara (CA), exp. 1638 .

20 Schäfer, 2003 [1935], 312.

21 Ver Suárez, 2001.

22 Schäfer, 2003 [1935], 312. 
por la facultad de nombrar teniente. ${ }^{23}$ Además, en 1638 tituló como caballero de Alcántara, completando así en pocos años un vertiginoso ascenso en su cursus honorum. ${ }^{24}$

La novedad en la provisión venal de uno de los puestos de mayor importancia de la Casa introdujo otras novedades en los procedimientos de la institución sevillana para entrar a desempeñar el oficio de contador. Así, aunque el mérito del dinero no le evitó a Villegas los trámites del sistema de fianzas, hubo una diferencia en su forma de obligarse en la cantidad de 30.000 ducados, suma que debían afrontar los jueces oficiales en concepto de fianzas. En una cédula con fecha 12 de agosto de 1634 dirigida a Juan de Santelices Guevara, regente de la Audiencia de Grados de Sevilla y comisionado por el Consejo de Indias para hacer reconocer las fianzas de los oficiales de la Casa, Villegas fue apremiado a obligarse en 30.000 ducados de fianza al igual que los contadores antecedentes en el puesto. Como era de esperar, Diego de Villegas protestó alegando que ya había demostrado ser «rico y abonado» con los 50.000 ducados de plata que pagó por el oficio, por lo que se ofreció como principal pagador, junto a su mujer, María de Villegas, e hipotecó el oficio por 30.000 ducados..$^{25} \mathrm{La}$ novedad se fundamentaba en el hecho de que, al tener el oficio en propiedad, se le permitió hacer una hipoteca sobre el mismo y, tras obligarse como principal pagador junto a su mujer e hipotecar el oficio por valor de 30.000 ducados en concepto de fianza, entró a servir uno de los principales puestos de la Casa en la sala de gobierno.

Pero la venalidad no afectó solamente al cargo recién enajenado pues, una vez que había pasado a manos privadas el oficio de contador juez oficial de la Casa, las facultades adquiridas por Villegas llegaron hasta los nombramientos de los oficios subordinados de la Contaduría que recaían bajo su potestad. Por lo tanto, como afirmó Andújar Castillo, no solo se estaba privatizando el empleo enajenado, sino también aquellos que dependían de la designación del titular. ${ }^{26}$ Usando esta facultad, Diego de Villegas hizo varios nombramientos que dependían directamente de su puesto de contador. Así, en 1637 hizo lo propio con Francisco del Valle en la plaza de oficial de la cuenta y razón de la labor del oro y la plata en pasta que se trae de las

23 La venta de este cargo ha sido apuntada en sus investigaciones por varios autores, entre otros: Schäfer, 2003 [1935], 312; Andújar Castillo, 2014; Gil Martínez, 2017a.

24 AHN, OM, CA, exp. 1638.

25 AGI, Escribanía, 1136C, f. 279r-284r.

26 Andújar Castillo, 2014. 
Indias, ${ }^{27}$ y unos años después, en 1640, designó como oficial mayor de la Contaduría de la Casa a Diego Ruiz de Villegas. ${ }^{28}$ Este último comenzaba así una carrera dedicada a los oficios de la Casa de la Contratación, en principio de la mano de los contadores, pues en 1644 fue nombrado tenedor de los libros de la Real Hacienda de la Casa por Fernando de Villegas, ${ }^{29}$ hijo del anterior contador, y en 1647 sería provisto como contador diputado de la Avería. ${ }^{30}$

La facultad adquirida por Diego de Villegas mediante el abono de 5.000 ducados adicionales para poder nombrar un teniente en su oficio no fue utilizada hasta que en 1643 nombró a su hijo, Fernando de Villegas, quien un año después, en 1644, entraría a servir la plaza en propiedad por la muerte de su padre. ${ }^{31}$ Sin embargo, su hijo Fernando inmediatamente designó como su teniente a Simón de Gaviola, que fue quien lo ejerció hasta 1646 cuando falleció. Fernando de Villegas lo desempeñaría desde entonces hasta que en 1668 fue provisto para gobernador y capitán general de la provincia de Venezuela, nombrando entonces como teniente a su yerno, Juan Tello Guzmán y Medina, y en 1675 renunció a los derechos de la plaza en su favor. ${ }^{32} \mathrm{Si}$, como veremos más adelante, Diego de Villegas tenía intereses en el comercio indiano, el propio Fernando de Villegas estuvo acudiendo a las juntas del Consulado siendo contador en $1646,{ }^{33}$ pero quien fuera su teniente hasta esa fecha, Simón de Gaviola, merece unas líneas que sirven de ejemplo de las relaciones entre los oficiales de la Casa y los miembros del Consulado sevillano favorecidas por la venalidad de los cargos de la Casa.

Simón de Gaviola, caballero de Santiago, miembro del Consulado en la década de 1630 —de hecho, estuvo asistiendo a dichas juntas hasta 1643 - , fue un personaje que trabajó para ambas instituciones. Pagador de varias rentas del Consulado, ${ }^{34}$ Gaviola ejerció el puesto de pagador de las armadas de la Carrera de Indias desde 1615 hasta 1637, pues en ese año obtuvo merced del rey para pasar el oficio a quien casara con su hija menor,

27 El nombramiento por parte de Diego de Villegas está en AGI, Indiferente, 2010. Véase la aprobación real en AGI, Indiferente, 434, lib. 8, f. 247v-248r.

28 AGI, Contratación, 5785, lib. 1, f. 165r-166v.

29 Ibidem, f. 209r-v.

30 Ibidem, f. 278r-280v.

31 AGI, Contratación, 5785, lib. 1, f. 424.

32 Donoso Anes, 1996.

33 Vila Vilar, 2016, 230; 2003b.

34 Concretamente fue administrador del impuesto de Balbas, véase: Vila Vilar, 1985; 2003b; 2016, 195 . 
Francisca, y mientras esto tenía efecto, pudo nombrar a alguien que lo sirviera. ${ }^{35}$ Esa facultad de nombrar teniente incluida en la merced fue usada por Gaviola en el mismo año 1637, cuando nombró como tal a Sebastián de Greña. ${ }^{36}$

Por tanto, la venta del cargo de contador juez oficial de la Casa de la Contratación, y su perpetuación en la familia Villegas, abrió la posibilidad para que uno de los tres principales puestos de juez oficial de la institución fuera ejercido por personajes muy cercanos y con estrechas relaciones con el comercio indiano, que, ocupando puestos clave en la institución que debía controlar y supervisar el comercio, tuvieron mayor facilidad para beneficiar sus intereses comerciales.

\section{Más allá de Sevilla: la venta del cargo de juez oficial de la Casa en Cádiz}

La venalidad de los cargos de la Casa de la Contratación pasó los límites de aquellos oficios que eran servidos en Sevilla para llegar hasta el puesto de juez oficial de la Casa en la ciudad de Cádiz. A comienzos del siglo XVII, el puesto de juez de la Casa en Cádiz estaba ocupado por Juan Bautista de Baeza y Polanco, que, aunque en 1613 - tras obtener merced del rey - traspasó el oficio a su hijo, Francisco Ruiz Polanco y Ayala, ${ }^{37}$ en 1623 volvió a ejercer el puesto por fallecimiento de este. ${ }^{38}$

El oficio de juez de Indias de Cádiz siguió en posesión de la misma familia hasta 1637, en que vacó por muerte de Juan Antonio Ruiz Polanco y Ayala, hermano del anterior e hijo del primero. La provisión de este oficio en 1637 formó parte de una intensa almoneda de cargos de la Casa de la Contratación que tuvo lugar durante aquella década ${ }^{39}$ y corrió a cargo de una junta que se había creado unos años antes para obtener recursos con los que vestir a los criados de la casa del rey, la denominada Junta de Vestir la Casa. ${ }^{40}$

Tras quedar vacante el oficio de juez de la Casa en Cádiz, fue presentada relación en el Consejo de Indias por Andrés de Munibe, oficial de la

35 Véase Díaz Blanco, 2017, 475-476.

36 AGI, Escribanía, 1136C, cuaderno 12, f. 239r-243v.

37 AGI, Escribanía, 1142A, cuaderno 74, f. 6r.

38 AGI, Escribanía, 1142A, cuaderno 73, f. 25r.

39 Andújar Castillo, 2014.

40 Gil Martínez, 2017b. 
Contaduría de la Casa de la Contratación, quien tenía una plaza supernumeraria de juez oficial de la Casa, que, según Vila Vilar, podría haber sido adquirida mediante el «mérito del dinero». ${ }^{41}$ Munibe reclamaba que corriera la merced que tenía concedida en este oficio de juez de Cádiz, pero su pretensión, que sería defendida por el Consejo de Indias, colisionó de lleno con la postura mantenida por la Junta encargada de beneficiar el oficio. La fórmula dispuesta por la Junta fue que Andrés de Munibe fuera «acomodado» con plaza supernumeraria de tesorero de la Casa de la Contratación, con los salarios y gajes propios del oficio, quedando de esta manera vía libre para la venta del puesto de juez de Cádiz. ${ }^{42}$

En abril de 1637, la Junta de Vestir la Casa había comenzado sus diligencias para proveer este oficio, e incluso llegó a proponer un comprador, Sancho de Urdaniz Lazcano, que ofreció 15.812 pesos pagados al contado. Ante estos hechos consumados por la Junta de Vestir la Casa, el Consejo de Indias manifestó su postura contraria a la venta del oficio de juez de Cádiz, elevando una consulta al rey en la que manifestaba su oposición a la venta. Justificaba su contrariedad por la administración de justicia que conllevaba el oficio de juez de Cádiz pero, ante la propuesta de la Junta, afirmó el sínodo que debía correr la merced que tenía concedida Andrés de Munibe, porque así se ahorraría la Real Hacienda el salario que había que darle en la Casa de la Contratación. ${ }^{43}$

Pero los argumentos del Consejo de Indias se extendieron más allá de los arriba mencionados. Consideraba el sínodo que el alto precio que había estipulado la Junta para la venta del oficio de Cádiz podía «mover a pensar que para sanear las costas y daños no se administrara aquel juzgado con la rectitud que pide el bien público». La amortización del precio pagado por el oficio hacía pensar a los consejeros de Indias que el pretendiente se saldría de los cauces del buen gobierno para lograr una rápida recuperación del dinero invertido. Pero la postura más clarividente de oposición del Consejo a la actitud mantenida por la Junta de Vestir la Casa se fundamentaba en las relaciones que Andrés de Munibe tenía con los comerciantes sevillanos. Decía el Consejo que tenía en Sevilla

trabazón y parentesco con muchos de los cargadores, y un hermano que ha sido cónsul y no es tan a propósito que resida como juez de la Casa [en Sevilla] por las depen-

41 Vila Vilar, 2003a, 438

42 Las consultas que tratan la venta de este oficio se encuentran en AGI, Indiferente, 760.

43 Idem. 
dencias que todos tienen de ella [...] y parece que viene a ser más útil y conveniente que se ejecute en Cádiz la merced que V. M. tiene hecha al dicho Andrés de Munibe. ${ }^{44}$

Efectivamente, como observó Vila Vilar, Andrés de Munibe tenía íntimas relaciones con los comerciantes más dinámicos de esta época, en concreto era hermano de Juan de Munibe, uno de los comerciantes que más plata recibió de América entre 1620 y 1645, ${ }^{45}$ además de cónsul del Consulado de Sevilla durante los años 1630 y $1631 .{ }^{46}$

Pero no todo fue unanimidad en el Consejo, pues el consejero Lorenzo Ramírez de Prado, a la sazón miembro de la junta encargada de beneficiar el empleo, emitió un voto particular en el que restaba importancia a las capacidades judiciales del oficio de juez de Indias de la ciudad de Cádiz, aludiendo a que disponía de menores funciones que los jueces de la Casa de la Contratación. Por supuesto, Ramírez de Prado estuvo de acuerdo en beneficiar el oficio, pero se oponía a que se vendiera a Sancho de Urdaniz pues, según el consejero, había otra persona dispuesta a satisfacer de contado 14.000 ducados de plata. Para reforzar su parecer y, a la vez, parte de lo dispuesto por la Junta de Vestir la Casa, estuvo en desacuerdo con el resto de consejeros en lo relativo a Andrés de Munibe, es decir, se opuso a que corriese la merced que tenía concedida en el oficio de juez de Cádiz. Afirmaba que, «aunque se sabe tiene parientes en Sevilla, en Cádiz obra solo y será de más inconveniente que sea juez a donde no tiene compañeros [...] y tanto más son interesados sus parientes en Cádiz que en la ciudad de Sevilla». ${ }^{47}$ Se oponía de esta manera a lo defendido por el Consejo y se ponía de parte de la Junta, reafirmando que el acomodo en la plaza supernumeraria de tesorero de la Casa de la Contratación para Munibe era la mejor solución por la conveniencia de vender el oficio de juez de Cádiz. Como vemos, Ramírez de Prado defendió los intereses de la Junta de Vestir la Casa por encima de los del Consejo de Indias.

En este episodio es posible percibir los conflictos de competencias, tan frecuentes durante el valimiento de Olivares, entre juntas ad hoc que nacen sin cometido alguno más allá de beneficiar o vender a perpetuidad efectos del patrimonio regio, como fue la Junta de Vestir la Casa, y los consejos de la monarquía que, exhibiendo su autoridad y defendiendo sus

44 Idem.

45 Vila Vilar, 2003a.

46 Vila Vilar, 2016, 239.

47 AGI, Indiferente, 760. 
competencias de aconsejar al monarca, se oponían a través de distintos argumentos jurídicos, morales y económicos a que este tipo de decisiones se les escaparan de sus competencias y jurisdicción.

No obstante, la postura defendida por la Junta de Vestir la Casa y también por Lorenzo Ramírez de Prado, como ya hemos dicho, miembro de dicha junta, fue la que finalmente se ejecutó. Las diligencias de la Junta para la venta del oficio comenzaron con el envío de varias cartas a distintas autoridades de Cádiz, siendo los destinatarios el obispo de la diócesis gaditana, don Juan de Velasco Castañeda, miembro del Consejo de Guerra, a cuyo cargo estaba la defensa de la ciudad, y Sebastián de Oleaga, veedor general de la Armada del mar Océano. A través de las misivas se les reclamaba información sobre las personas que podían, por un lado, ejercer el oficio mientras se vendía, pues Nuño de Villavicencio — regidor perpetuo de Cádiz, que lo ejercía en interinidad - era una «persona poderosa que estorba para que no se trate la venta del oficio y por esta causa convenía nombrar a otra persona en ínterin», y, por otro lado, pedían conocer qué personas había en Cádiz que pudieran comprar el oficio con carácter vitalicio. ${ }^{48}$

Nuño de Villavicencio era una persona poderosa en la ciudad de Cádiz y él mismo pujó por el oficio de juez de Cádiz, encontrándose con la negativa de los miembros de la Junta. Es reseñable que la opinión sobre Nuño de Villavicencio que mantenían los ministros de la Junta de Vestir la Casa, entre los que se encontraba un consejero de Indias como Lorenzo Ramírez de Prado, fuera negativa, mientras que para la Casa de la Contratación este era el candidato idóneo para hacerse con el oficio. Así se lo transmitió la Casa en 1637 al monarca en una carta tras conocer la noticia de que el puesto de juez del Juzgado de Indias de Cádiz había sido puesto en almoneda. ${ }^{49}$

En septiembre de 1637, Gregorio de Leguía y Albalaez fue nombrado juez del Juzgado de Indias de Cádiz mientras se vendía el oficio, desplazando así a Nuño de Villavicencio y dejando vía libre para la venta. ${ }^{50}$ En el mismo mes se despachó comisión desde la citada junta a Alonso Ramírez de Prado —oidor de la Chancillería de Granada, hermano del consejero de Indias y también miembro de la Junta, Lorenzo Ramírez de Prado-, que se encontraba en Cádiz, para que ajustara el beneficio del puesto por una

48 Archivo General de Simancas (AGS), Consejo y Junta de Hacienda (CJH), lib. 162, 87.

49 AGS, CJH, 1770, f. 580r.

50 AGI, Contratación, 5785, lib. 1, f. 130r-131r. 
vida, con los salarios y emolumentos que tenía Juan Antonio Ruiz Polanco y Ayala y la facultad de nombrar teniente. ${ }^{51}$

Alonso Ramírez de Prado cumplió con brevedad el cometido que le había sido encargado y a los pocos días de recibir la cédula para el beneficio del oficio informaba al secretario de la Junta, Matías Fernández Zorrilla, que tenía un comprador dispuesto a ofrecer 10.000 ducados de plata al contado. Se trataba de Jerónimo Rodríguez Roca, caballero de Santiago y teniente de capitán general de la artillería del mar Océano, quien, en julio de 1638, depositó los 10.000 ducados de contado en poder de Sebastián Vicente, depositario de la Cámara del rey. ${ }^{52}$ Pero Jerónimo Rodríguez Roca no ejerció el oficio. Unos meses antes de que entregara la citada suma, Alonso Ramírez se congratulaba en una epístola a Matías Fernández Zorrilla de que la Junta hubiese tenido por bien beneficiar dicho oficio en la persona de Rodríguez Roca, y pedía que se hicieran los despachos con el nombramiento pues el comprador debía nombrar teniente por su eminente salida de Cádiz hacía Madrid donde iba a contraer matrimonio. ${ }^{53}$

Así, tras hacerse con el oficio, Jerónimo Rodríguez Roca nombró de forma provisional un teniente que lo ejerciera, ${ }^{54} \mathrm{y}$ en septiembre de 1639 nombró como tal a Pedro Fernández Moreno, tomando la razón la Contaduría de la Casa de la Contratación y comenzando a ejercer en el oficio de juez de Cádiz al mes siguiente. ${ }^{55}$

Pedro Fernández Moreno, natural de Garachico en la isla de Tenerife ${ }^{56}$ no era desconocido entre los oficios de la Carrera de Indias. En 1637 había comprado por 554.000 maravedís de plata una licencia de navío de entre los efectos que beneficiaba por el Consejo de Indias su presidente, el conde de Castrillo, ${ }^{57}$ y un año después, en 1638, compró a perpetuidad por 10.000 pesos el oficio de veedor de las flotas de Nueva España de la Casa de la Contratación. ${ }^{58}$

Por tanto, merced a la compra del oficio de juez de la Casa en Cádiz y a su patrimonialización por parte de Jerónimo Rodríguez Roca, se dieron

51 AGS, CJH, lib. 162, f. 88r-89v.

52 AGI, Contratación, 5785, lib. 1, f. 146v-150v.

53 AGS, CJH, 1770, s/n. f. $146 \mathrm{r}$.

54 Se trató de Diego de la Breña Concha, vecino de Sevilla. AGI, Contratación, 5785, lib. 1,

55 AGI, Contratación, 5785, lib. 1, f. 158v.

56 AHN, OM, Expedientillos, n. 3178.

57 AGI, Contaduría, 73.

58 AHN, E, 2312. Véase también en AGI, Contratación, 5785, lib. 1, f. 150r. 
las condiciones para que al frente del Juzgado de Indias de Cádiz, como encargado del despacho de las embarcaciones que se cargaban en la ciudad gaditana y su bahía, se situara a una persona que tan solo unos años antes había adquirido una licencia de navío y, como veremos más adelante, era dueño de una nao con la que comerciaba con las Indias.

\section{De la provisión venal al desempeño del cargo de juez oficial de la Casa}

Una vez analizados los procesos venales para el acceso a esos cargos de la Casa de la Contratación — contador juez oficial y juez de la Casa en Cádiz_- pasamos a estudiar el ejercicio de los mismos por parte de ambos compradores, Diego de Villegas y Pedro Fernández Moreno.

\section{Diego de Villegas: el poder del dinero en el puesto de contador juez oficial}

Diego de Villegas, primer juez oficial que accedió al cargo mediante compra, tenía relaciones muy cercanas con el comercio sevillano con las Indias. La llegada de Villegas a uno de los puestos de la sala de gobierno de la Casa tras haber abonado 50.000 ducados lo convirtió en un hombre poderoso en Sevilla y, además, debido a la patrimonialización y perpetuación del oficio y la facultad de nombrar teniente, el puesto de contador estuvo durante esta coyuntura en manos de personajes que guardaban intereses en el comercio indiano.

Sin embargo, Diego de Villegas, pese a ser un personaje poderoso en Sevilla debido, entre otras cuestiones, al cargo que desempeñaba en la Casa, no estuvo a salvo de las denuncias que llegaban al Consejo de Indias sobre un posible mal uso de su oficio. Así, a principios de 1640 llegó al Consejo de Indias un memorial firmado por Diego de Vargas y Tejada que denunciaba ciertas prácticas ilícitas del contador de la Casa de la Contratación. Villegas era acusado de estar cargando mercancías para las Indias, en concreto, vino y vinagre que procedían de una finca de su propiedad en Torre de las Arcas, en el término de Bollullos de la Mitación, haciéndolas pasar en los registros de la Casa de la Contratación como propiedad de su suegra, Ana Maldonado. Además, se le acusaba de forzar a los dueños y maestres de naos a que le llevaran sus mercancías, pues en caso contrario, debido a la «mano fuerte de su oficio», no les daba registro a sus naos para 
ir a las Indias. Y por si estas acusaciones no revestían gravedad, también se le achacaba que traía la plata producto de esas ventas fuera de registro. ${ }^{59}$

Debido a la importancia de lo denunciado en dicho memorial, fue el propio presidente del Consejo de Indias, el conde de Castrillo, quien se hizo cargo del asunto. Lo hizo dirigiéndose a uno de sus hombres de confianza en Sevilla, Juan de Góngora, quien en esa fecha se encontraba desempeñando un puesto de oidor en la Audiencia de Grados de aquella ciudad y, además, servía varias comisiones del Consejo de Indias relacionadas con el fraude en los registros de ida y vuelta de las flotas de Indias. En carta con fecha 2 de abril de dicho año, Castrillo emplazó a Góngora a que con todo secreto se informase si la persona firmante del memorial era conocida y se encontraba en Sevilla, y estando en la ciudad hispalense, reconociera el memorial y le tomara declaración extrajudicialmente. Góngora no localizó al autor del memorial y devolvió a Castrillo la averiguación en el mismo punto en que estaba cuando llegó a sus manos. ${ }^{60}$

Mas los memoriales denunciando dichas prácticas del contador siguieron llegando al Consejo, esta vez con distintas firmas, como el enviado bajo la rúbrica de Juan Rodríguez, por lo que Castrillo volvió a cometer a Góngora que de forma extrajudicial «porque en este negocio haya secreto y no ande por los oficios, escriba o resuelva como le pareciese apurar las noticias que se hallaren con fundamento contra este ministro». Del mismo modo, Castrillo avisó que en dicho memorial se citaban «libros y testigos», y advertía a Góngora que «procure v.m. con toda maña y recato inquirir y averiguar lo que hubiere escribiendo por su misma mano sin otra solemnidad». Como se aprecia, la información quedaba reservada y secretamente guardada entre Castrillo y Juan de Góngora, pues en la misma misiva, afirmaba el conde que «de todo me informará v.m. y me escribirá v.m. confidentemente porque fiamos de su celo y cuidado [...] para que lo gobierne con la puntualidad y verdad que espero cuando solo yo estuviera de por medio». ${ }^{61}$

Las acusaciones contra Villegas eran de importancia ya que, además de conculcar la prohibición de comerciar con las Indias que tenían los ministros de la Casa de la Contratación, se le acusaba de usar el poder que le daba su oficio para obligar a los dueños y maestres de naos a que le llevaran

59 Autos y averiguación contra don Diego de Villegas, juez oficial de la Casa sobre haber cargado para las Indias mucha cantidad de vino y haber traído lo procedido sin registro y haber obligado a los dueños y maestres de naos que se llevasen muchas botijas. AGI, Escribanía, 1136A, cuaderno 3, f. 352 r.

60 AGI, Escribanía, 1136A, cuaderno 3, f. 368r.

61 Ibidem, f. 370r-v. 
mercancías bajo coacción de no permitirles hacer viaje. Pero ¿fueron los dueños y maestres de naos los denunciantes de las supuestas prácticas de Villegas? Los autores de los memoriales no fueron localizados por Juan de Góngora, por lo que no fue posible hacérselo reconocer, pero la cantidad de información de libros de cuentas y de diferentes personas que podían certificar lo que dichos memoriales citaban, le dieron credibilidad ante el presidente del Consejo de Indias, que decidió encargar la investigación a otra persona.

Fue así cuando el administrador de los almojarifazgos de Sevilla, ${ }^{62}$ Jerónimo de Sanvítores de la Portilla, se encargó de las pesquisas extrajudiciales contra Villegas con las mismas condiciones de «secreto y recato» que habían sido confiadas a Juan de Góngora con anterioridad y siendo, de nuevo, su único interlocutor en la Corte el presidente del sínodo indiano. El cambio de investigador se debió, según lo afirmó Castrillo, a «los impedimentos naturales de Juan de Góngora». ${ }^{63}$ No conocemos cuáles fueron estos impedimentos a los que hacía referencia el conde, pero es muy probable que Góngora se encontrara inmerso en alguna de las comisiones encargadas por el Consejo de Indias en aquellos años. Lo cierto es que con esta decisión, Castrillo colocaba al frente de la averiguación a un personaje que tenía lazos de paisanaje con Diego de Villegas, pues ambos eran burgaleses. Esto no impidió que Sanvítores fuera más diligente que Góngora y que pusiera, aunque tímidamente, más luz sobre la oscuridad de lo denunciado en aquellos memoriales.

Sanvítores logró averiguar quién estaba tras la autoría de los memoriales contra Villegas. Se trataba de Francisco Gaspar de Solís, quien reconoció haber mandado dar traslado a dos oficiales, Diego de Vargas y Juan Rodríguez, y estos a su vez los habían enviado al Consejo de Indias. Según García Fuentes, Francisco Gaspar de Solís, caballero de Calatrava, era cosechero y exportador de vino y aceite,${ }^{64}$ lo que puede darnos una idea del motivo de la denuncia a Villegas por cargar estos productos del agro sevillano desde su cargo de juez de la Contratación perjudicando a otros exportadores.

Francisco Gaspar de Solís se ratificó ante Jerónimo de Sanvítores en lo que denunciaban aquellos memoriales, y añadió más testigos que podían corroborarlo. La mayoría de ellos prestaron testificación ante el comisionado. Los testigos citados por Gaspar de Solís fueron los siguientes:

62 Sobre los almojarifazgos de Sevilla, véase Melón Jiménez, 2018.

63 AGI, Escribanía, cuaderno 3, 1136A, f. 362r.

64 García Fuentes, 1977a, 22; 1977b, 51. 
TESTIGOS CITADOS EN EL MEMORIAL CONTRA DIEGO DE VILLEGAS

\begin{tabular}{|l|l|}
\hline \multicolumn{1}{|c|}{ Testigo } & \multicolumn{1}{c|}{ Datos del testigo } \\
\hline Pedro del Argos & Caballero de Santiago \\
\hline Juan de Castañeda & \\
\hline Francisco de Castañeda & Vecino de Bollullos de la Mitación \\
\hline Andrés López de Ampuero & Vecino de Bollullos de la Mitación \\
\hline Juan Manuel de Céspedes & Vecino de Bollullos de la Mitación \\
\hline Alonso García & \\
\hline Pedro Vargas Ponce de León & Veinticuatro de Sevilla / comerciante ${ }^{65}$ \\
\hline Francisco Díaz de Velasco & Comerciante \\
\hline Tomás Manito & \\
\hline Pedro de Luna & Flamenco / Dueño de nao \\
\hline Pedro Bengorri & General de Armada ${ }^{67}$ \\
\hline Don Luis Fernández de Córdoba & Dueño de nao $0^{68}$ \\
\hline Bernabé de Ibarra & Maestre de nao de Bernabé de Ibarra \\
\hline Juan Rodríguez Villanueva & Comerciante \\
\hline Martín de Sanartu & Veinticuatro de Sevilla / comerciante \\
\hline Antonio de Melo & De la orden de San Francisco \\
\hline Fray Antonio de Córdoba & \\
\hline
\end{tabular}

Fuente. Elaboración propia a partir de AGI, Escribanía, 1136A, cuaderno 3, f. 353r-358v.

La averiguación de Sanvítores comenzó a dar resultados y, en efecto, como denunciaba Francisco Gaspar de Solís, Diego de Villegas era el propietario de una hacienda en Bollullos de la Mitación procedente de las capitulaciones matrimoniales que había alcanzado en 1635 para su enlace con María de Bocanegra Maldonado. ${ }^{71}$ Esta última, vecina de Sevilla, hija de Pedro Gutiérrez de Bocanegra y de Ana Maldonado, había estado casada con anterioridad con el almirante Alonso de Mújica y Buitrón, quien en

65 Vila Vilar, 2016, 189.

66 Ibidem, 204.

67 Domínguez Ortiz, 2002. Pérez-Mallaína, 2007.

68 Fernández González, 2000, 360.

69 Vila Vilar, 2016, 222.

70 Ibidem, 207.

71 AGI, Indiferente, 434, lib. 6, f. 248. 
1633 murió en la mar. ${ }^{72}$ Dos años más tarde casó de nuevo con Diego de Villegas, quien al parecer también había quedado viudo de su anterior esposa María de Villegas. ${ }^{73}$

Como ya se ha comentado, la primera alusión de la denuncia se motivaba en que el contador de la Casa cargaba la cosecha de vino y aceite procedentes de su finca, además de otra mucha que compraba, y los despachos los sacaba en cabeza de Ana Maldonado, su suegra. Fueron varios los testigos que ratificaron esta primera parte del memorial de Francisco Gaspar de Solís, ${ }^{74}$ pero variaban en la cantidad que exportaba Villegas. Para su comprobación, Jerónimo de Sanvítores examinó los registros del vino que se había cargado para las Indias desde 1635 hasta fin de 1640, comprobando que en cabeza de Ana Maldonado se habían despachado 45.266 arrobas de vino. Pero Sanvítores advirtió que la suegra de Villegas tenía una cosecha propia en la villa de Manzanilla, por lo que esa fuente no era determinante al respecto. ${ }^{75}$ Por ello hubo que hacer nuevas pesquisas y el próximo paso que dio el comisionado fue comprobar los registros de los fieles del vino de las villas de Manzanilla y Bollullos de la Mitación entre los años 1635 y 1640, los registros de la Casa de la Contratación a nombre de Ana Maldonado y los puertos por donde se había cargado dicha producción, ya que la cosecha de Manzanilla era cargada en el puerto de las Nueve Suertes y la de Bollullos de la Mitación en los puertos de Coria y Venta de la Negra. El resultado fue el siguiente:

\section{REGISTROS DE LOS FIELES DEL VINO PROCEDENTES DE LAS COSECHAS DE ANA MALDONADO Y DIEGO DE VILLEGAS (1635-1640)}

\begin{tabular}{|c|c|}
\hline $\begin{array}{c}\text { Registros de Ana Maldonado } \\
\text { en Manzanilla }\end{array}$ & $\begin{array}{c}\text { Registros de Diego de Villegas } \\
\text { en Bollullos de la Mitación }\end{array}$ \\
\hline 26.778 arrobas de vino & 40.292 arrobas de vino \\
\hline
\end{tabular}

Fuente: Elaboración propia a partir de AGI, Escribanía, 1136A, cuaderno 3, f. 415r-416r.

72 Bienes de difuntos de Alonso de Mújica y Buitrón. AGI, Contratación, 960, n. 5.

73 María de Villegas era natural de Bárcena, situado en el mismo valle de Toranzo a escasa distancia de Entrambasmestas de donde era natural Diego de Villegas. Véase: Pruebas para la obtención del título de caballero de la Orden de Santiago de Fernando de Villegas, natural de Lima, año 1631. AHN, OM, Caballeros Santiago, exp. 8963.

74 En concreto Pedro del Argos, Juan de Castañeda, Andrés López de Ampuero, Alonso García y Pedro de Vargas Ponce de León.

75 AGI, Escribanía, 1136A, cuaderno 3, f. 353r-358v. 
En el cuadro anterior se reflejan los registros de los fieles del vino de cada una de las villas donde Ana Maldonado y Diego de Villegas tenían sus cosechas. Sin embargo, en los registros de la Casa de la Contratación, la cantidad de vino registrada por Ana Maldonado para su exportación a las Indias entre 1635 y 1640 fue de 46.696 arrobas de vino, muy superior a lo producido en su finca de Manzanilla. Además, los puertos por donde se había cargado la mayoría de lo registrado por Ana Maldonado fueron los de Coria, Merlín y San Juan de Aznalfarache, cuando lo producido en Manzanilla se cargaba por el puerto de las Nueve Suertes. Para Sanvítores estaba claro: la producción de la finca de Ana Maldonado era muy inferior a lo que reflejaban los registros de la Casa, además de que todo lo cargado en los primeros puertos era de la producción de Diego de Villegas en la hacienda de Torre de las Arcas, en tanto que los despachos se habían sacado en nombre de Ana Maldonado.

Con respecto al segundo hecho denunciado en el memorial, relativo a que Diego de Villegas obligaba, «con la mano fuerte de su oficio», a los dueños y maestres de naos a que llevasen por fuerza pipas y botijas de vino impidiendo el despacho hasta que lo hiciesen, los testigos examinados reconocieron que el contador les había pedido que llevaran pipas y botijas de vino en varias ocasiones, pero siempre les afirmaba que eran de su suegra. Al menos nominalmente, cual lo atestiguaban los registros, así era. Solamente el general don Luis Fernández de Córdoba afirmó que había oído decir a Pedro Bengorri, dueño de nao, que Villegas le había vendido 400 botijas para que las embarcara en la nao que fue a Honduras en 1639. Sobre este punto no hubo una averiguación clara, pues los dueños de naos citados en el memorial no fueron examinados, según Sanvítores, por no encontrarse en Sevilla. ${ }^{76}$

En lo relativo al tercer punto denunciado en el memorial, sobre la plata que habría entrado por el puerto de Venta de la Negra, procedente del producto de la venta de las cosechas de Diego de Villegas, Sanvítores comunicó a Castrillo que los testigos «no dicen este punto con fundamento más que por noticia», y aunque pidió al conde que le autorizara a ver los registros de la plata que se había traído en retorno de las pipas y botijas de vino, estos no fueron analizados. ${ }^{77}$

A su vez, Jerónimo de Sanvítores informó al conde de Castrillo, que «don Francisco Gaspar de Solís, don Pedro de Vargas Ponce de León,

76 Ibidem, f. 359r-361r.

77 Idem. 
don Juan Manuel de Céspedes y otros caballeros de esta ciudad [Sevilla] eran enemigos declarados de Diego de Villegas». Las razones de la enemistad, según Sanvítores, provenían de la propiedad de las alcabalas de Bollullos de la Mitación, en manos de Villegas, quien no había querido encabezar el lugar, sino cobrar por entero. Además, Villegas no les había permitido adehesar sus términos y había pretendido comprar la jurisdicción de Bollullos, a lo que los citados se oponían. Aun habiendo comprobado que algo de razón tenían en sus denuncias, según Sanvítores, estas fueron las verdaderas causas del envío de los memoriales. ${ }^{78}$ En la última carta que envió el comisionado a Castrillo, el 16 de febrero, sobre este asunto, Sanvítores decía que «la parte [Diego de Villegas] llevó noticia», justificando así ante el presidente del sínodo indiano la dificultad de conocer más sobre el asunto. ${ }^{79}$

De lo que no hay duda, pues lo demostró Sanvítores en sus pesquisas, es que Diego de Villegas cargaba el producto de su hacienda para las Indias a nombre de su suegra, pero también parece evidente que Sanvítores no quiso indagar más sobre la cuestión e hizo lo posible por resolverlo con rapidez, justificando además ante Castrillo la dificultad que revestía investigar a una persona tan poderosa como Villegas.

Una vez en manos del conde de Castrillo las averiguaciones realizadas por Sanvítores, el Consejo de Indias dictó auto con fecha 10 de febrero de 1642 en el que, tras haber reconocido dicha indagación, le otorgó veracidad a las cargas para las Indias que había estado haciendo Diego de Villegas a nombre de Ana Maldonado producto de sus heredades en la Torre de las Arcas,

en contravención de las cédulas y ordenanzas y prohibiciones de tratar y contratar en las Indias, mayormente los ministros de Su Majestad, que con la mano poderosa que tienen defraudan los tributos, derechos y dan mal ejemplo a los demás poniéndose en ocasión de no usar bien sus oficios, pues precisamente han de disimular a lo más sus delitos por conseguir el que no se lleguen a saber los suyos de que resulta de servicio de S.M. y gran daño y menoscabo de su real hacienda y de la causa pública y recta administración de justicia. ${ }^{80}$

El sínodo indiano mandó que para remedio y «para que sean castigados conforme a derecho de los delitos que han cometido» se prosiguiera

78 Ibidem, f. 353r-358v.

79 Ibidem, f. 361r.

80 Ibidem, f. 424r. 
esta averiguación en la visita de la Casa de la Contratación y sus ministros que estaba próxima a comenzar. ${ }^{81}$ De esta manera, fue remitida esta causa al visitador Juan de Góngora el 13 de febrero de 1642, que continuaría con las pesquisas sobre los hechos denunciados en el memorial de Francisco Gaspar de Solís en el marco de la visita a la Casa de la Contratación que inició en junio de ese mismo año de $1642 .{ }^{82}$

\section{Pedro Fernández Moreno: de comerciante a juez de la Casa en Cádiz}

Las ventas de oficios a perpetuidad permitían al propietario nombrar como tenientes - léase arrendarlos - a terceras personas. Este fue el caso de la plaza de juez de la Casa en Cádiz que, tras ser adquirida por Jerónimo Rodríguez Roca, nombró por su teniente a Pedro Fernández Moreno. Es posible deducir que este nombramiento fue un arrendamiento pues, según un poder que otorgó en 1640 Jerónimo Rodríguez Roca al veinticuatro de Sevilla Pedro de Rosas para que pudiera cobrar de Pedro Fernández Moreno 4.000 ducados de plata de la segunda paga de una escritura de obligación suscrita entre ambos, podríamos intuir que dicha deuda se debía al arrendamiento del oficio de juez de Indias en Cádiz que, dos años más tarde, en 1642, Pedro Fernández Moreno abonó a Pedro de Rosas. ${ }^{83}$

Hasta aquí nada fuera de lo común en la transmisión de los oficios por tenencia, pero ya hemos advertido que Fernández Moreno no era desconocido en los oficios de la Carrera de Indias, y que la venalidad le había servido para hacerse con una licencia de navío y el puesto de veedor de las flotas de Nueva España.

Como apuntamos en otro trabajo, las denuncias que llegaban al Consejo de Indias sobre la connivencia de los oficiales reales en fraudes y excesos cometidos a la llegada de las flotas habían señalado al juez de Cádiz, ${ }^{84}$ pero si cambiamos la fuente hacia los protocolos notariales gaditanos, advertimos que Pedro Fernández Moreno no solo era cómplice de estos fraudes y abusos que se cometían en la bahía gaditana a la llegada de las flotas, sino que, desde su puesto de juez de la Casa en Cádiz, formaba parte activa del comercio gaditano con las Indias.

81 Idem. Véase Heredia López, 2017

82 AGI, Escribanía, 1136A, cuaderno 3, f. 352r.

83 AGI, Escribanía, 1142A, cuaderno 75, f. 21r-22v.

84 Vila Vilar, 2003b. 
Pedro Fernández Moreno poseía una nao propia, llamada San Diego, de porte de 400 toneladas que, en el año 1640, es decir, estando ya ejerciendo el puesto de juez de la Casa en la ciudad de Cádiz, tenía aprestada con visita y registro por su juzgado, es decir, se había dado a sí mismo la pertinente autorización para hacer viaje a Tierra Firme en los galeones del cargo del general don Jerónimo Gómez de Sandoval. Conocemos este asunto por una escritura de compraventa que suscribió con Lázaro de Tompes Larreandi, vecino de Cádiz, para la venta de la nao San Diego con el registro y visita, es decir, preparada para hacer el viaje a Tierra Firme, por 12.000 ducados de plata, que según afirmó Fernández Moreno en aquella escritura, le había pagado al contado ${ }^{85}$ Pero en realidad, como demostró unos años después la visita de Juan de Góngora al Juzgado de Indias de Cádiz, Lázaro de Tompes hizo viaje a las Indias en 1640 siendo la nao propiedad de Pedro Fernández Moreno, pues se repartieron las ganancias de aquel viaje, y fue entonces, en 1641, cuando se hizo con la nao San Diego. ${ }^{86}$ Es decir, la escritura de compra-venta de la nao fue simulada y en realidad Lázaro de Tompes actuó como testaferro de Pedro Fernández Moreno.

A su vez, Pedro Fernández Moreno estableció compañías de comercio con otros mercaderes de la bahía gaditana para enviar mercancías desde Cádiz a La Habana. Fue el caso del compromiso alcanzado entre Fernández Moreno y Antonio Páez Castillejo en 1639 para que este último llevara en la nao San Diego, propiedad del juez, unas mercancías consignadas a nombre de Antonio de Venalcázar, vecino de La Habana, quien las recibió, las vendió, y de cuya venta resultó un montante de 62.418 reales de plata, de los cuales, Pedro Fernández Moreno se quedó con 38.274 reales, la mitad más los costos del viaje. ${ }^{87}$

Sus negocios continuaron, pues en 1645 dio un poder a Pedro López Ramales, Bartolomé Guerrero y Diego Ruiz, vecinos de Cádiz y pasajeros en la flota que ese año se disponía a hacer viaje a Tierra Firme, para que en su nombre pudieran cobrar «cualesquiera maravedís, ducados, reales, barras de oro y plata, frutos de la tierra y otras cualesquiera cosas en cualquier género y suerte que sean que les hubiere entregado don Juan de Padilla, alcalde de corte de la ciudad de los Reyes». Además, hizo extensible el poder para que pudieran cobrar de otras personas, pero remarcaba que lo

85 Archivo Histórico Provincial de Cádiz (AHPC), Protocolo 3042, f. 262r-264r.

86 AGI, Escribanía, 1142A, cuaderno 74, f. 25v-27r.

87 AHPC, Protocolo 4401, f. 743r. 
procedido debía ser entregado a su persona.$^{88}$ Son muchos más los negocios privados que mantenía Pedro Fernández Moreno desde su cargo de juez oficial de la Casa en Cádiz que se pueden rastrear en los protocolos notariales gaditanos pero, por su clarividencia, nos limitaremos a los citados más arriba.

Como vemos, la compra del oficio de juez de la Casa en Cádiz permitió que su propietario nombrara como su teniente - arrendara el oficio- a un personaje que mantenía unos fuertes intereses comerciales, prohibidos para tal desempeño. En la visita que tomó Juan de Góngora al Juzgado de Indias de Cádiz entre 1645 y 1646, en el marco de la inspección general de la Casa de la Contratación, dichos negocios saldrían a la luz con unas consecuencias funestas para Pedro Fernández Moreno.

\section{Conclusiones}

La venalidad de cargos de la Casa de la Contratación en las décadas de los años 30 y 40 del siglo XVII afectó a todos los estamentos de la institución, pero sin duda, la almoneda de puestos tan importantes como el de contador juez oficial y el de juez oficial de la Casa en Cádiz, enajenados por vez primera en aquella coyuntura, abrió a sus compradores un horizonte de posibilidades, lícitas e ilícitas, debido al enorme poder que gozaban desde esos dos cargos centrales de la maquinaria de la institución sevillana. La compra de oficios se convirtió así en un mecanismo de acceso al epicentro del poder y la información en los asuntos del comercio indiano, pues se enajenaron, a perpetuidad, uno de los tres puestos de juez oficial de la sala de gobierno y, vía beneficio, el puesto encargado de los registros de las embarcaciones del comercio gaditano con las Indias. Pero además, al concentrar en sus manos tan significativo poder, también se les presentó a sus compradores la posibilidad de defender sus propios intereses en detrimento de la misma Casa de la Contratación.

La patrimonialización del oficio de contador juez oficial de la Casa en la persona de Diego de Villegas en 1634 inició el camino de futuras enajenaciones de puestos de la sala de gobierno de la institución, como demostró Francisco Andújar en su estudio sobre la venalidad de cargos de la Casa. Sin duda, la llegada a Sevilla de la familia Villegas debió de

88 AHPC, Protocolo 4402, f. 191r-v. 
suponer un estruendo en la ciudad hispalense. Diego de Villegas era una persona poderosa, con unas relaciones importantes con sectores muy bien situados en la economía limeña, como su hermano, el financiero Bernardo de Villegas. La asombrosa suma depositada por el oficio de contador así lo atestiguaba. La importancia del puesto era clave, y así además lo demuestra la pugna mantenida por Andrés de Munibe para adquirirlo, llegando este último incluso a suplicar al rey que, tras la venta del cargo a Villegas, le hiciera una merced equivalente. De esta pugna es posible inferir cómo distintas familias con intereses en el comercio indiano, como eran los Munibe y los Villegas, para una mejor defensa de sus intereses estaban intentando hacerse con importantes puestos de poder en la Casa de la Contratación.

A su vez, hacerse con uno de estos cargos con la facultad de nombrar a los oficiales subordinados del oficio, le otorgaba a su propietario un enorme poder, ya que podía situar a sus hechuras y parientes en estos oficios. Es probable que la coincidencia en el apellido en el nombrado como oficial mayor de la Contaduría de la Casa, Diego Ruiz de Villegas, respondiera a esta lógica.

Diego de Villegas fue uno de los principales ministros de la Casa que fueron investigados en la visita que Juan de Góngora inició a dicha institución en 1642. Pero antes del inicio de la inspección, las denuncias que llegaron al Consejo sobre una mala praxis en el ejercicio de su oficio hicieron que el presidente del sínodo abriera una investigación particular sobre este ministro.

Como hemos visto, las acusaciones revestían gravedad, pues «con la mano fuerte de su oficio» no solo estaba beneficiando sus intereses comerciales sino que estaba perjudicando los de terceros, en este caso, los de otros exportadores y dueños y maestres de naos. Las redes que tejió Villegas en Sevilla, con un matrimonio ventajoso con María de Bocanegra Maldonado, le convirtió además en un exportador de vino, producto de su finca de Torre de las Arcas en Bollullos de la Mitación donde, al parecer, Diego de Villegas había situado sus miras de ennoblecimiento al intentar comprar la jurisdicción del lugar, ganándose por este motivo la animadversión de otros exportadores de la zona. Aunque esta fuera la causa última que motivó la denuncia enviada al Consejo por Francisco Gaspar de Solís, había un sustrato de verdad en las acusaciones allí vertidas y las pesquisas realizadas por Jerónimo de Sanvítores demostraron que Villegas, desde su puesto de contador y utilizando como testaferro a su suegra, Ana Maldonado, estaba negociando en el comercio indiano, perjudicando de esta manera a otros 
exportadores del agro sevillano. Así lo consideró también el Consejo de Indias cuando pidió que la causa abierta contra Diego de Villegas se incorporara a la visita que iba a acometer Juan de Góngora a la Casa de la Contratación.

Fueron más las denuncias que llegaron al Consejo previas a la visita de Juan de Góngora sobre malos usos del oficio de Diego de Villegas, pero este, que murió en 1644, al igual que su hijo Fernando, que siguió en el puesto hasta 1668, no recibieron sentencia alguna en dicha visita a pesar de haberse probado que no procedían en su oficio con la satisfacción requerida. Por algún motivo que desconocemos se salvaron de la suspensión de cargos y penas pecuniarias dictadas por el Consejo de Indias a partir de 1654 a los culpados en la visita.

En el caso del juez de la Casa en Cádiz, hemos documentado el proceso de la venta del oficio, enajenado por vez primera en esta coyuntura, y que formó parte de la almoneda de cargos que sacudió con fuerza la Casa de la Contratación en las décadas de 1630 y 1640.

Es importante resaltar algunas cuestiones de dicho proceso de venta del oficio. En primer lugar, la pugna abierta por varias personas con intereses distintos por hacerse con el oficio. Andrés de Munibe, hermano de Juan de Munibe, uno de los comerciantes más activos de la década de 1630 y cónsul del Consulado de Sevilla durante 1630 y 1631, como ya hiciera en 1634 con el puesto de contador, volvió a intentar hacerse con el puesto de juez de Cádiz en 1637. Sin duda Munibe representaba los intereses del Consulado sevillano por hacerse con puestos de poder en la Casa de la Contratación. En segundo término, Nuño de Villavicencio, regidor perpetuo de Cádiz y representante de una familia con intereses en el comercio gaditano con las Indias. En cierto modo, en estas pretensiones de hacerse con el cargo de juez de la Casa en Cádiz se estaban contraponiendo dos formas de entender la plaza comercial gaditana, por una parte, la cercana a los intereses de los hombres del comercio sevillano, y de otra parte, la vinculada a los intereses de los hombres del comercio gaditano. En segundo lugar, los conflictos de competencias entre diferentes espacios de poder en la Corte. Por un lado, el Consejo de Indias que se oponía a la venta del oficio de juez de Cádiz apoyando las pretensiones de Andrés de Munibe para que corriera la merced que tenía de juez oficial supernumerario de la Casa en la plaza de juez de Cádiz y, por otro lado, las pretensiones de la Junta de Vestir la Casa y del consejero Lorenzo Ramírez de Prado, a la sazón, miembro de la Junta, ignorando los argumentos de contrariedad del Consejo sobre «el 
trabazón y parentesco» de Munibe con muchos de los cargadores sevillanos y la nula conveniencia de que este fuera «acomodado» en la Casa con la futura de tesorero. Finalmente prevaleció la opinión de la Junta y el oficio fue beneficiado en una persona que no lo iba a ejercer, pues así se lo transmitió Alonso Ramírez de Prado, comisionado para la venta del oficio a Matías Fernández Zorrilla, secretario de la Junta.

La transmisión por tenencia de Rodríguez Roca en la persona de Pedro Fernández Moreno formaba parte de lo habitual en estos casos. Sin embargo, la facultad adquirida por el propietario para nombrar teniente, dejaba al Consejo de Indias sin poder ejercer ningún control sobre la rectitud y buen hacer de la persona que iba a ocupar el oficio. Dicho en otros términos, dejaba en manos de Jerónimo Rodríguez Roca la decisión de arrendarlo al mejor postor sin comprobación alguna por parte del Consejo de las calidades del arrendador.

De este modo, la tenencia del oficio de juez de Cádiz fue ejercida por Pedro Fernández Moreno, un personaje con una dilatada trayectoria venal y que sería otro de los principales ministros investigados en la visita que Juan de Góngora inició a la Casa de la Contratación a partir de 1642. Pedro Fernández Moreno, desde su puesto de juez de la Casa en Cádiz, se mostró al mismo tiempo como un activo comerciante con las Indias, tráfico que practicaba en principio desde su propia embarcación, para más adelante hacerlo en compañía con otros mercaderes gaditanos. Por estas razones, Pedro Fernández Moreno fue condenado en 1654 al pago de 14.400 ducados de plata y privación de sus oficios de veedor de las flotas de Nuevas España y de juez de la Casa en Cádiz. ${ }^{89}$ Entre los cargos que le hizo el visitador y por los que fue condenado constó que había tratado y contratado enviando mercancías a las Indias y trayéndolas fuera de registro en los navíos que despachaba por su Juzgado, obligando a los dueños de naos a que llevaran sus mercancías por fuerza, además de haber tenido un navío propio, que había enviado a las Indias y participado en otro. ${ }^{90}$

En síntesis, aunque los comportamientos irregulares ya existieran en la Casa de la Contratación con anterioridad a la venta de puestos de tan alta responsabilidad como lo eran los de juez oficial, tanto en Sevilla como en Cádiz, la posibilidad de comprar estos cargos proporcionó a Diego de Villegas y a Pedro Fernández Moreno una excelente oportunidad para la defensa de sus intereses comerciales, valiéndose para ello de prácticas que

89 AGI, Contaduría, 230.

90 Los cargos contra Pedro Fernández Moreno se encuentran en AGI, Escribanía, 1182. 
podríamos denominar como corruptas y que serían perseguidas y castigadas por la monarquía a través de la visita de Juan de Góngora a la institución sevillana.

Recibido el 1 de junio de 2018 Segunda versión el 1 de octubre de 2018

Aceptado el 18 de octubre de 2018

\section{Referencias bibliográficas}

Álvarez Nogal, Carlos, «Los maestres de plata durante el reinado de Felipe IV. Nombramientos y beneficios», en Gutiérrez Escudero, A. (ed.), Ciencia, economía y política en Hispanoamérica colonial, Sevilla, Consejo Superior de Investigaciones Cientificas, 2000, 139-159.

Andújar Castillo, Francisco, «Los contratos de venta de empleos en la España del Antiguo Régimen», en Andújar Castillo, F. y Felices de la Fuente, M. (eds.), El poder del dinero: ventas de cargos y honores en el Antiguo Régimen, Madrid, Biblioteca Nueva, 2011, 63-82.

Andújar Castillo, Francisco, «La Casa de Contratación de Sevilla y la venalidad de los cargos (1634-1717)», en Núñez Roldan, F. y Gamero Rojas, M. (eds.), Entre lo real y lo imaginario. Estudios de Historia Moderna en homenaje al prof. León Carlos Alvarez Santaló, Sevilla, Universidad de Sevilla, 2014, 47-73.

Andújar Castillo, Francisco y Felices de la Fuente, María del Mar (eds.), El poder del dinero: ventas de cargos y honores en el Antiguo Régimen, Madrid, Biblioteca Nueva, 2011.

Díaz Blanco, José Manuel, «En torno a la ocultación de la venalidad: las naturalezas en la Carrera de Indias (1621-1643)», en Andújar Castillo, F. y Felices de la Fuente, M. (eds.), El poder del dinero: ventas de cargos y honores en el Antiguo Régimen, Madrid, Biblioteca Nueva, 2011, 314-328.

Díaz Blanco, José Manuel, «Servicio al rey y progreso social en el siglo XVII: los oficiales de la Avería en la Casa de la Contratación», en Maffi, D. y García Hernán, E. (eds.), Estudios sobre Guerra y Sociedad en la Monarquía Hispánica. Guerra marítima, estrategia, organización y cultura militar (15001700), Valencia, Albatros Ediciones, 2017, 471-492.

Domínguez Ortiz, Antonio, Política y Hacienda de Felipe IV, Madrid, Editorial de Derecho Financiero, 1960.

Domínguez Ortiz, Antonio, «Los Generales y Almirantes de la Carrera de Indias en el S. XVII», en Antonio Domínguez Ortiz... y Dos Hermanas, Sevilla, Ayuntamiento de Dos Hermanas, Miscelánea Oripense, 2002, 75-89. 
Donoso Anes, Rafael, Una contribución a la historia de la contabilidad: análisis de las prácticas contables desarrolladas por la tesorería de la Casa de la Contratación de las Indias de Sevilla (1503-1717), Sevilla, Universidad de Sevilla, 1996.

Fernández González, Fernando, Comerciantes vascos en Sevilla, 1650-1700, Vitoria-Gasteiz, Diputación de Sevilla / Eusko Jaularitza, 2000.

García Fuentes, Lutgardo, «Exportación y exportadores sevillanos a Indias, 16501700», Archivo Hispalense, LX, 184, Sevilla, 1977a, 1-39.

García Fuentes, Lutgardo, «Cien familias sevillanas vinculadas al tráfico indiano (1650-1700)», Archivo Hispalense, LX, 185, Sevilla, 1977b, 1-54.

Gelabert González, Juan Eloy, La bolsa del rey: rey, reino y fisco en Castilla (15981648), Barcelona, Grijalbo, 1997.

Gil Martínez, Francisco, «Los maestres de plata de la Carrera de Indias durante el periodo de Olivares», en Iglesias Rodríguez, J. J. y García Bernal, J. J. (eds.), Andalucía en el mundo Atlántico. Agentes y escenarios, Madrid, Sílex, 2016, 243-264.

Gil Martínez, Francisco, «La venta de cargos de Indias en tiempos de Olivares: el conde de Castrillo», Anuario de Estudios Americanos, 74, 1, Sevilla, 2017a, 97-126.

Gil Martínez, Francisco, La Junta de Vestir la Casa (1636-1643). Juntas, financiación de la Corte y venalidad, Madrid, Polifemo, 2017b.

Heredia López, Alfonso Jesús, «La visita a la Casa de la Contratación y Consulado de Sevilla en 1642: orígenes y motivaciones de un instrumento de control», Tiempos Modernos. Revista electrónica de Historia Moderna, 8, Madrid, 2017, 388-410.

Jiménez Estrella, Antonio, «Poder, dinero y ventas de oficios y honores en la España del Antiguo Régimen: un estado de la cuestión», Cuadernos de Historia Moderna, 37, Madrid, 2012, 259-272.

Melón Jiménez, Miguel Ángel, «Los cauces legales del comercio en Andalucía. Aduanas y rentas de Sevilla y Cádiz (1543-1752)», en Iglesias Rodríguez, J. J.; García Bernal, J. J. y Díaz Blanco, J. M. (eds.), Andalucía en el mundo atlántico. Ciudades y redes, Madrid, Sílex, 2018, 263-300.

Pérez-Mallaína, Pablo Emilio, «Generales y Almirantes en la Carrera de Indias. Una investigación pendiente», Chronica Nova. Revista de Historia Moderna de la Universidad de Granada, 33, Granada, 2007, 285-332.

Ruiz Martín, Felipe, «Las finanzas de la Monarquía Hispánica en tiempos de Felipe IV (1621-1665)», en Tedde de Lorca, P. (coord.), Las finanzas de Castilla y la Monarquía Hispánica (siglos XVI y XVII). Homenaje a Felipe Ruiz Martín, Valladolid, Universidad de Valladolid, 2008, 193-317.

Schäfer, Ernesto, El Consejo Real y Supremo de las Indias. Historia y organización del Consejo y de la Casa de Contratación de las Indias, Valladolid, Junta de Castilla y León, 2003 [1. a ed. 1935]. 
Suárez, Margarita, Desafíos transatlánticos. Mercaderes, banqueros y el estado en el Perú virreinal, 1600-1700, Lima, Instituto Francés de Estudios Andinos, 2001.

Vila Vilar, Enriqueta, «Los gravámenes de la Carrera de Indias y el comercio sevillano: el impuesto de Balbas», en Torres Ramírez, B. y Hernández Palomo, J. J. (eds.), Andalucía y América en el siglo XVII. Actas de las III Jornadas de Andalucía y América, Sevilla, Escuela de Estudios Hispano-Americanos, CSIC, 1985, vol. 1, 253-270.

Vila Vilar, Enriqueta, «Los maestres de plata: un resorte de poder en el comercio con Indias», en Sarabia Viejo, M. J. (ed.), De Puebla de los Ángeles a Sevilla. Homenaje al Dr. José Antonio Calderón Quijano, Sevilla, Universidad de Sevilla, 1997, 119-131.

Vila Vilar, Enriqueta, «El tesorero Andrés Munibe: entre la Casa y el Consulado», en Acosta Rodríguez, A.; González Rodríguez, A. y Vila Vilar, E. (eds.), La Casa de la Contratación y la navegación entre España y las Indias, Sevilla, Universidad de Sevilla, 2003a, 433-447.

Vila Vilar, Enriqueta, «El poder del dinero: la Casa y los Consulados de Sevilla y Cádiz», en Vila Vilar, E. (ed.), España y América: un océano de negocios. Quinto Centenario de la Casa de la Contratación, 1503-2003, Madrid, Sociedad Estatal de Conmemoraciones Culturales, 2003b, 147-160.

Vila Vilar, Enriqueta, El Consulado de Sevilla de mercaderes a Indias: un órgano de poder, Sevilla, Instituto de la Cultura y las Artes de Sevilla, 2016. 